with oil, and is normally used for providing a selflubricating bearing. The purpose of its incorporation in this syringe is to provide a thin film of oil between the piston and the barrel. To avoid losing the oil from this 'oilite' bush the syringe must be assembled before sterilization. With an accurately fitted piston a pressure of $50 \mathrm{lb}$. per sq. in. can be easily obtained, and at this pressure there is only a slight and insignificant leakage of the inoculum past the piston. Brass and phosphor-bronze were used for the construction of this first model ; but there is no reason why stainless steel could not be employed or the brass syringe could be cadmium plated. This is mentioned as it may be thought desirable to avoid the possibility of some of the metallic ions in these alloys exerting a deleterious effect on the inoculum.

By the use of this syringe it has been found that up to 10 c.c. of liquids of various viscosities can ke readily injected at one site into the skin of the neck of cattle. A full account of this work will be published elsewhere.

I am indebted to Mr. M. Gilhee of the National Institute for Medical Research, Hampstead, for his painstaking work in constructing this syringe.

W. M. HENDERSON.

(Research Olficer,

Foot-and-Mouth Disease

Virus Research Station,

Research Committee.)

Pirbright, Surrey.

Oct. 28.

${ }^{1}$ Curasson, G., Dischamps, A., and Andryesky, P., Bull. Acad. vét. Fr. $2,383(1029)$.

\section{Boiling Point and Viscosity}

IN connexion with the communication by $A$. Dutta ${ }^{1}$ connecting the ratio of $\eta / \eta_{B}$ with that of $T / T_{B}$, where $\eta$ represents viscosity, $T$ temperature and the suffix $B$ the boiling point condition, and obtaining a 'universal curve' for several gases it may be of interest to add the following facts.

From considerations of the mechanisms of both viscosity and evaporation, a relationship was obtained in 1939 for liquids in which the ratio $\eta / \eta_{B}$ was found to be a function of $T / T_{B}$, expressed graphically ${ }^{2}$. It was found that certain groups of liquids, for example, homologous series, fell on a common curve. Further, there were three distinct regions describing associated, metallic and normal liquids. The position of these curves were further governed by the 'shape' of the molecule, but the most important consideration was the evidence from a fuller report of this work than my note appearing in NATURE, that "one law governs all viscous flow in all states of matter and that there must be a solitary equation giving the change, with temperature, of magnitude of viscous forces in flowing matter"3. This was in contradistinction from the prevalent view that the mechanism of viscosity in liquids is essentially different from that of gases. To formulate this universal law governing the viscositytemperature relationship, the general equation for liquids,

$$
\log \eta=K+K_{1}\left(\frac{T}{T_{B}}\right)+K_{2}\left(\frac{T}{T_{B}}\right)^{2}+K_{3}\left(\begin{array}{l}
T \\
T_{B}^{-}
\end{array}\right)^{3},
$$

was solved4. It was found that all paraffins containing four or more carbon atoms are governed by

$$
\begin{aligned}
\log \eta_{P}=6 \cdot 283- & 18 \cdot 572\left(\frac{T}{T_{B}}\right) \\
& +17 \cdot 505\left(\frac{T}{T_{B}}\right)^{2}-5 \cdot 900\left(\frac{T}{T_{B}}\right)^{3},
\end{aligned}
$$

and further, that for the other liquids the viscosity at the same value of $\left(\frac{T}{T_{B}}\right)$ as that for the paraffin was governed by

$$
\begin{aligned}
\log \eta & =A-B\left(6 \cdot 283-\log \eta_{P}\right) . \\
& =C+B \log \eta_{P} .
\end{aligned}
$$

Further ${ }^{5}$, as

$$
\log \eta=A f(T)+\frac{Q}{2 \cdot 3 R T},
$$

where $Q$ is energy of activation of viscosity, therefore

$$
\begin{aligned}
\Delta\left(\frac{Q}{T}\right)=-2 \cdot 3 R \Delta & \left\{18.572\left(\frac{T}{T_{B}}\right)\right. \\
& \left.-17.505\left(\frac{T}{T_{B}}\right)^{2}+5.900\left(\frac{T}{T_{B}}\right)^{s}\right\}
\end{aligned}
$$

Thus the energy of activation, for the viscosity of liquids, in parallel with that of evaporation, was found to decrease, ultimately, with temperature and vanish at the critical point. This is due to the fact that the energy of activation is the result of two energies, a positive and a negative energy, both increasing with the temperature but at unequal rates, becoming equal at the critical temperature. Above the critical temperature the negative energy is of greater arithmetical value than the positive, indicating a rise of viscosity of a gas with temperature. All this involves working under the pressure of the saturated vapour. For low pressures the influence of pressure is negligible.

At the present time work is proceeding on passing from the liquid to the gaseous state through the critical temperature, in the hope that if the single equation for all states works as well with gases as liquids under these conditions, it may $\mathrm{ke}$ extended to vapours and gases under different conditions.

There appears to be no doubt that the use of $T / T_{B}$ as a criterion for levels of temperature affords distinct possibilities to the understanding of the mechanism of viscosity-possibilities not so readily available using other 'reduced temperature' scales.

\section{Department of Oil Engineering and Refining,}

The University, Edgbaston, Birmingham.

${ }^{2}$ Dutta, A., Nature, 152, 445 (1943).

${ }^{2}$ Nissan, A. H., and Clark, T. V. W., NATuRe, 143, 722 (1939).

sissan, A. H., Clark, I. V. W., and Nash, A. W., J. Inst. Petrol., 26, $207(1940)$

4 Nissan, A. H., Phil. Mag., Ser. 7, 32, 441 (1941).

s Dunstan, A. E., and Nissan, A. H., Phil. Mag., Ser. 7, 34, 479 (1943).

\section{A Dental Survey of the British Isles}

ThIs is a general report on the effects of war-time diet on the dentition of 9,400 youths in England and Wales, Isle of Man, Northern Ireland and Eire. In the last-named place until April 1943, meat, eggs and milk, sweets and chocolate have not been rationed; sugar and tea have since been controlled and butter only partially. 